\title{
The Association of Moral Distress and Demographic Characteristics in the Nurses of Critical Care Units in Tehran, Iran
}

\author{
Nooredin Mohamadi ${ }^{1}$, Faezeh Fakoor ${ }^{2}$, Hamid Haghani ${ }^{3}$, Sedigheh Khanjari ${ }^{4}$
}

\begin{abstract}
Background \& Aim: Nurses need peace of mind in the workplace in order to provide proper patient care and accurately perform their complicated responsibilities. On the other hand, workplace stress and ethical issues affect the nursing profession. Moral distress is an inevitable issue in the nursing profession and occurs when nurses want to operate based on knowledge and what is morally accepted. Nurses experience moral distress based on their occupational role and professional status, and various factors are involved in the emergence of moral distress, including organizational factors, collaborative and group relationships, and factors related to patients and their treatment processes. However, nurses working in intensive care units (ICUs) are more at risk of moral distress due to stressful situations. In addition, the highest level of moral distress in ICU is due to nonstandard care and treatment caused by a shortage of staff. Another factor that contributes to this issue is working with the unqualified staff at various nursing and medical levels. Moral distress can affect nurses' work-life and have various impacts on the life of staff, patients, and health organizations. This could lead to confusion, fear, anxiety, and lack of power in nurses, which results in job dissatisfaction and intention to leave in nurses. Therefore, the present study aimed to determine the relationship between moral distress and demographic characteristics of nursing in ICUs of medical training centers of Tehran, Iran.

Materials \& Methods: This cross-sectional, correlational, and descriptive research was performed on 200 nurses working in ICUs of medical training centers in Tehran, affiliated with Iran and Shahid Beheshti universities of medical sciences in 2018. A stratified sampling method with proportional allocation was used to enroll participants, and CCU, ICU, and ICU-OH were considered as categories. Data were collected using a demographic characteristics questionnaire, which included background information of nursing staff. In addition, a 24-item moral distress scale by Corly was applied, which assessed the frequency and intensity of moral distress, and its items were scored based on a five-point Likert scale. In this regard, the mean of 24 items was calculated to estimate the moral distress score. In addition, the score range was 0-96. Data analysis was performed in SPSS version 16 using descriptive statistics (frequency distribution, mean, and estimation of numerical indicators), and inferential statistics such as independent t-test and (to evaluate the relationship between intensity and frequency of moral distress with demographic characteristics of the participants), analysis of variance (for pairwise comparison) and Scheffé's method.

Results: In this research, $79.5 \%$ of the participants working in intensive care units $(\mathrm{n}=200)$ were female, and the age range of 30-39 years had the highest frequency (46.5\%). In addition, 57.5\% of the subjects were married, $22 \%$ of whom had no children. Most subjects $(55 \%)$ had a work experience of more than 10 years, which showed the presence of experienced nurses in these wards. Regarding the level of education, $87.5 \%$ of the subjects had a BSc and the rest had an MSc. Moreover, $56.5 \%$ of the participants were permanently employed. The majority of the participants $(78.5 \%)$ worked in rotating shifts, and nurses with 10-14 night shifts per month $(27.5 \%)$ had the highest frequency in the number of night shifts. The results of the analysis of variance and t-test showed no

\footnotetext{
1. Associate Professor, Nursing Care Research Center, School of Nursing and Midwifery, Iran University of Medical Sciences, Tehran, Iran

${ }^{2}$. MS Nursing, School of Nursing and Midwifery, Iran University of Medical Sciences, Tehran, Iran (Corresponding author) Tel: $0912776635 \quad$ Email: fakoorfaezeh@gmail.com

${ }^{3}$. Instructor, Department of Biostatistics, School of Health, Iran University of Medical Sciences, Tehran, Iran

${ }^{4}$. Associate Professor, Nursing Care Research Center, School of Nursing and Midwifery, Iran University of Medical Sciences, Tehran, Iran
} 
significant relationship between the frequency of moral distress and variables of gender, age, marital status, number of children, level of education, work experience, employment status, work shift, number of night shifts per month and ethics training. Overall, there was no significant relationship between the frequency of moral distress and the demographic characteristics of nurses. According to the results, the mean and standard deviation of the frequency of moral distress was estimated at $48.96 \pm 18.21$, which was near the medium score of the tool (49), and the mean and standard deviation of intensity of moral distress was reported at $52.04 \pm 18.43$, which was higher than the medium score (49). Meanwhile, we found a significant relationship between the frequency of moral distress and the type of ward $(\mathrm{P}=0.014)$. However, the frequency of moral distress was significantly lower in the ICU-OH ward, compared to CCU $(\mathrm{P}=0.040)$ and ICU $(\mathrm{P}=0.018)$. Nonetheless, this difference was not significant between ICU and CCU. In addition, there was a significant difference between the intensity of moral distress and ward $(\mathrm{P}=0.030)$. Furthermore, moral distress intensity was significantly lower in ICU-OH, compared to $\mathrm{CCU}(\mathrm{P}=0.005)$ and ICU $(\mathrm{P}=0.008)$, and no significant difference was found between ICU and CCU.

Conclusion: In the present research, we observed a moderate frequency and intensity of moral distress in nurses working in intensive care units, which could have a negative impact on patient care and the health of personnel. According to the results, there was a significant relationship only between the ward and moral distress. In addition, there was no significant association between moral distress and ethics training. According to our findings, there was no significant relationship between the demographic characteristics of the participants and their moral distress. Therefore, other factors such as organizational support, socioeconomic factors, and other predisposing factors of moral distress should be assessed in this regard. In addition, training the staff and familiarizing them with factors of moral distress could play a role in decreasing this issue in nurses working in intensive care units. In this respect, training could be carried out by nursing managers and instructors in the form of researcher, counselor, and planner to familiarize nurses with moral distress and decrease this factor in these individuals. It is recommended that our findings be used by nursing managers and authorities to develop proper treatment policies to decrease moral distress in nurses working in intensive care units.

\section{Keywords: Moral Distress, Nurse, Intensive Care Unit}

\section{Conflict of Interest: No}

How to Cite: Mohamadi N, Fakoor F, Haghani H, Khanjari S. The Association of Moral Distress and Demographic Characteristics in the Nurses of Critical Care Units in Tehran, Iran. Iran Journal of Nursing. 2019; 32(121):41-53.

Received: 11 Sep 2019

Accepted: 10 Dec 2019 


\title{
ارتباط ديسترس اخلاقى با مشخصات جمعيت شناختى يرستاران بخش مراقبت ويره شهر تهران
}

\author{
نور الدين محمدى '، فائزه فكور 'r، حميد حقانى '، صديقه خنجرى
}

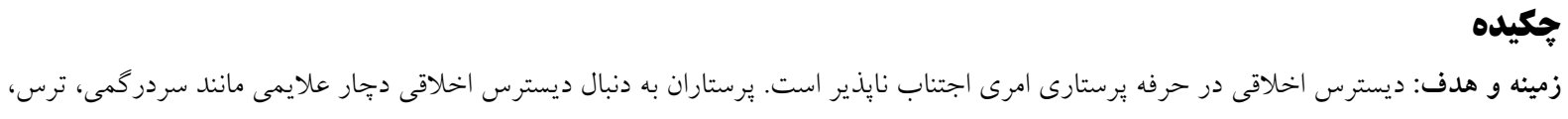

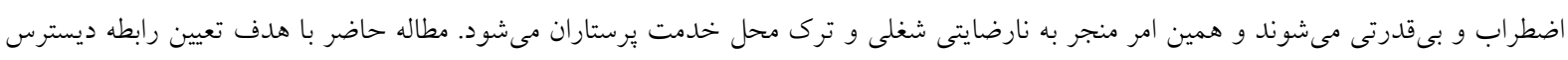

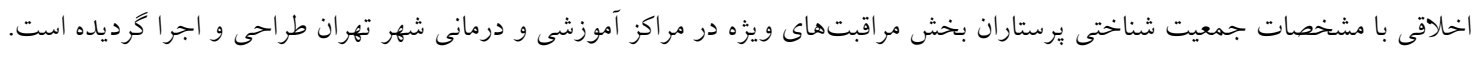

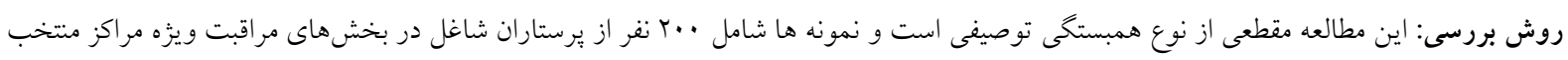

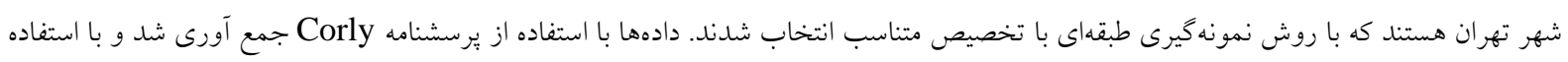

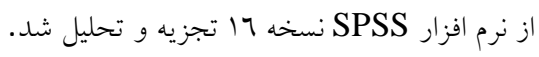

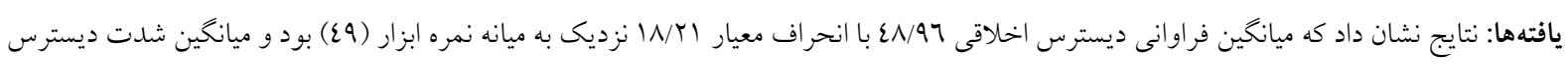

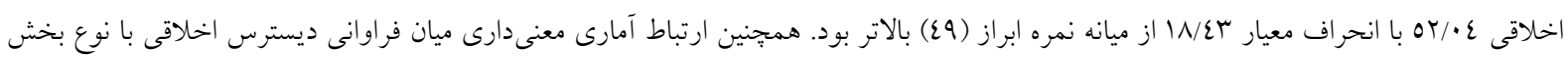

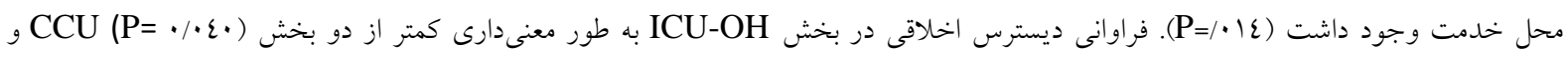

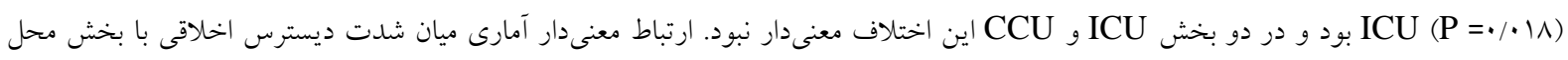

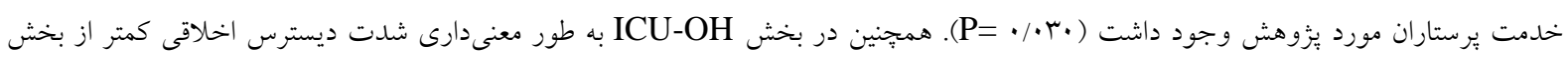

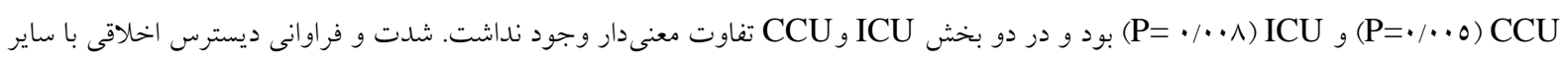
متغيرهاى جمعيت شناختى ارتباط آمارى معنى دارى نداشتند.

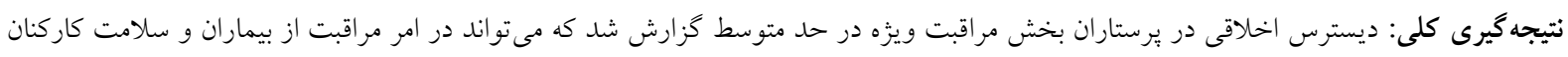

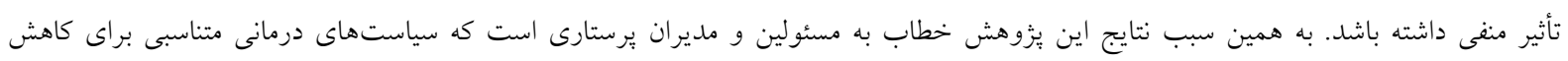
ديسترس اخلاقى در ميان ير ستار ان بخش مر اقبت بنهاى ويزّه اتخاذ نمايند

كليد وازهها: مالتيبل اسكلروزيس، مراقبين بيماران، كيفيت زندگى، اضطراب مرگ تعارض منافع: ندارد تاريخ دريافت: • •

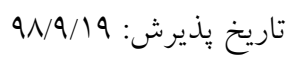

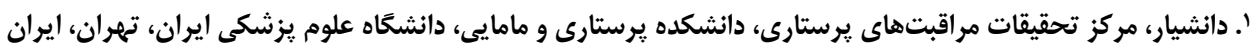

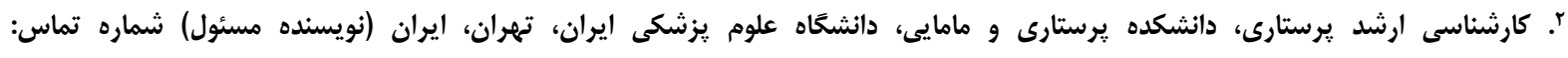

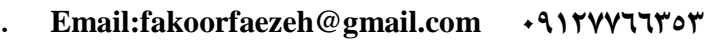

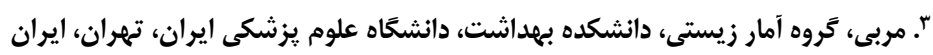

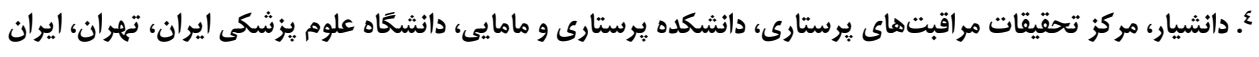


عوامل متعددى منجر به ديسترس اخلاقى مى شوند از

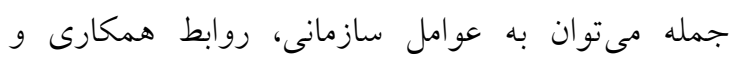
كروهى، عوامل مربوط به بيماران و روندهاى درمانى اشاره كرد. علل سازمانى شامل كمبود امكانات و تجرهيزات،

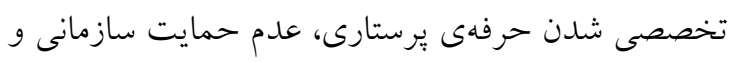

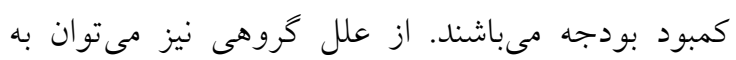

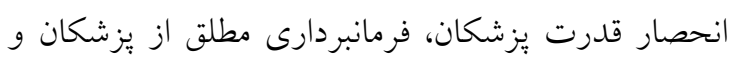

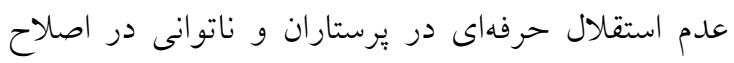

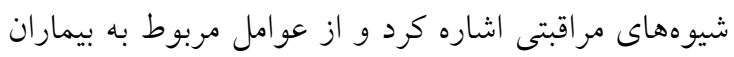
و روندهاى درمانى مىتوان درمانهاى تهاجمى، مسائل

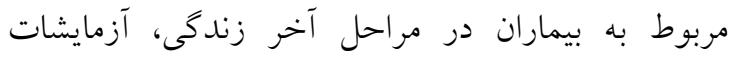
غيرضرورى و درمانهاى نامناسب و ناكافى را مطرح نمود(v). از ديخر عوامل مؤثر بر ديسترس اخلاقى در دران

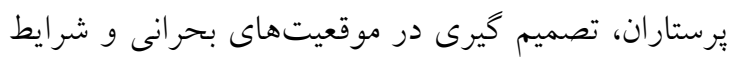

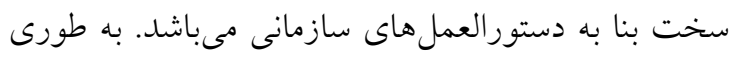

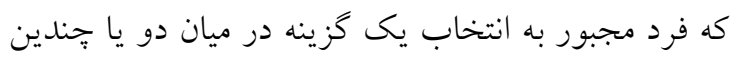

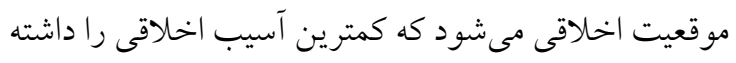

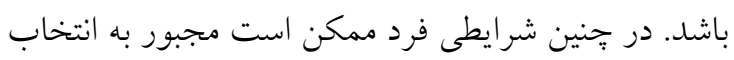
در شر ايطى باشد كه برخلاف عقيده درست اخلاقى اوست.

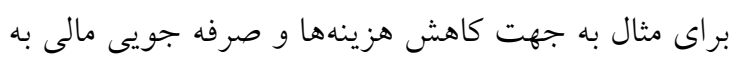

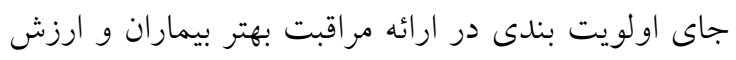
هاى حرفهاى بر روى مسائل مالى و كاهش هزينهها تمركز

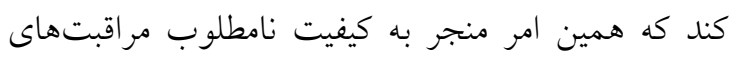

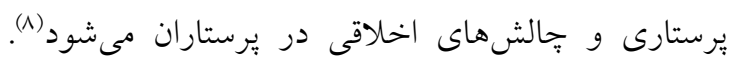

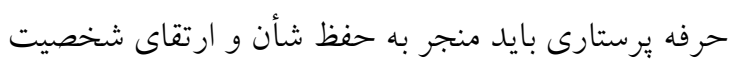

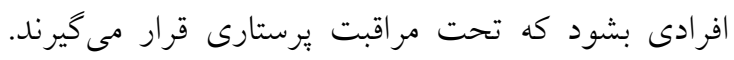

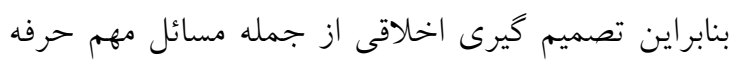
يرستارى مىباشد و اين تصميم كيرى جزء اساسى ترين

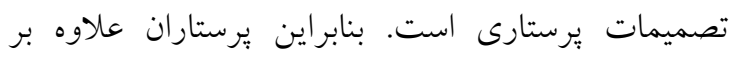

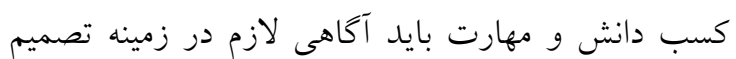
كيرىهاى اخلاقى را نيز كسب كنند (9).

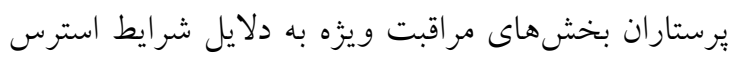
زا در معرض ديسترسهاى اخلاقى بيشترى قرار مى كيرند؛

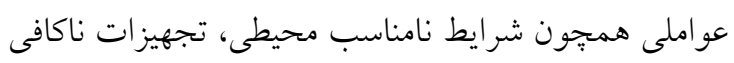

\section{مقدمه}

اساس و بايه حرفه يرستارى محافظت از سلامت افراد جامعه است و با توجه به نقش مهم اين حرفه در حفظ سلامت افراد جامعه، امروزه يرستاران نقش مهمى در نظام

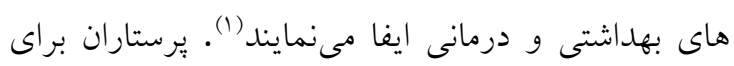
ارائه مراقبت صحيح به بيمار ان و انجام وظايف بييجيده خود نيازمند آرامش روانى در محيط كار خود هستند. از طرف ديخر، مسائل اخلاقى و تنشهاى محيط كار بر حرفه يرستارى تأثير گذار مىباشند. يرستاران در محيط كارى خود مسئول هماهنكى با ساير متخصصان و برستاران ديخر نيسر هستند تا بتوانند برنامه ريزى و سازمان دهى را به كونهاى مهاى انجام بدهند كه شرايط لازم براى مراقبت از بيمار فراهم شود(r). در سالهاى اخير، در تحقيقات برستارى توجه زيادى به ديسترس اخلاقى شده است و در ميان نظريه يردازان يرستارى، Jampton اولين كسى است كه به له مفهوم ديسترس اخلاقى يرداخته و آن را توصيف كرده است(r). ديسترس اخلاقى يا بريشانى اخلاقى زمانى اتفاق

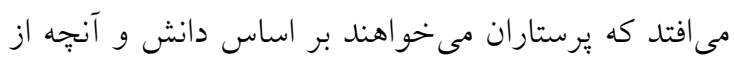
نظر اخلاقى صحيح است، عمل كنند اما با اختلاف نظر اخلاقى و شناختى مواجه مىشوند و يا مىتواند به دلايلى آلى مانند بى احترامى به حقوق بيمار و يا درگيرى در محيط كار رخ دهد و همين مساله در امر سلامت و مراقبت بيماران

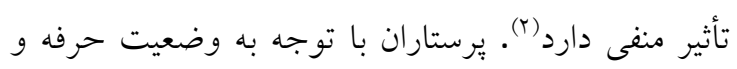
نقش شغلى خود، مورد ديسترس هاى اخلاقى قرار مى گيرند و عوامل متعددى مىتواند منجر به ديسترسهاى اخلاقى

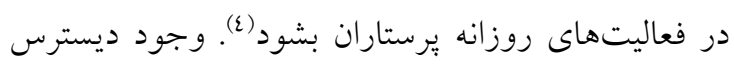

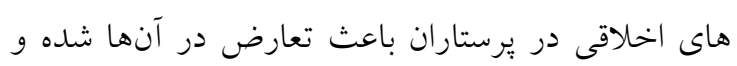

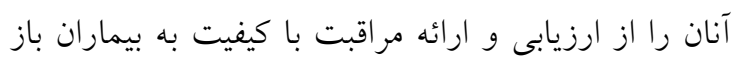
مىدارد. اين شرايط خود زمينه را براى نقص در روند بهبودى و افزايش ملت بسترى بيماران فراهم مى كند (0). ديسترس اخلاقى يديدهاى شايع در حرفه يرستارى است و

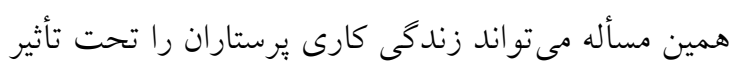
قرار بدهد و تأثيرات متفاوتى را بر روى زندگى كاركنان، بيماران و سازمانهاى بهداشتى داشته باشد (7). 
حرفه بيشتر است (10). مطالعه O'Connel نشان داد كه

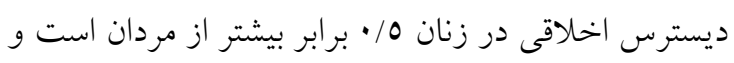

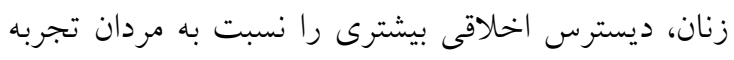
مى كنند (ع). در مطالعه عباس زاده، ارتباط معنى دارى ميان

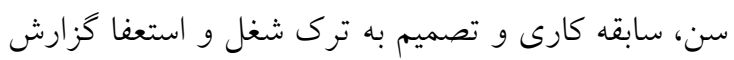

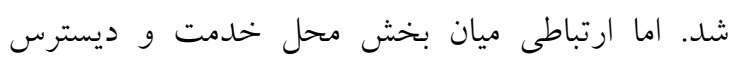

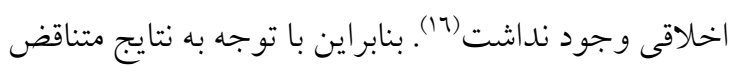

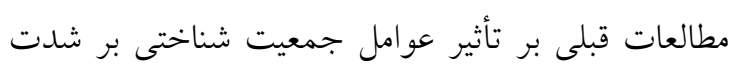

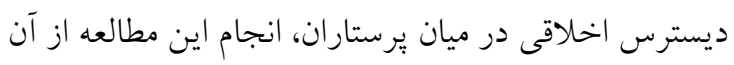

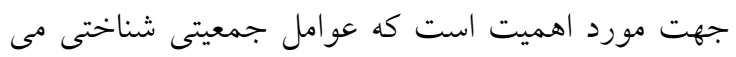

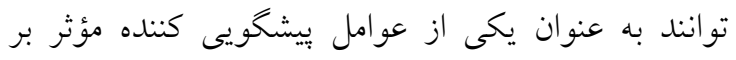

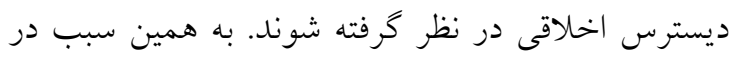

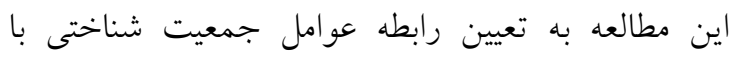
ديسترس اخلاقى در ميان يرستار ان بخشهاى مراقبت ويزه كه در معرض خطر ديسترس اخلاقى هستند، يرداخته شد.

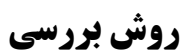

اين مطالعه مقطعى از نوع همبستكى توصيفى است كه در

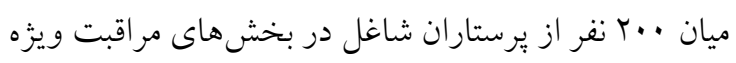
مر اكز آموزشى و درمانى شهر تهران وابسته به دانشعاه علوم

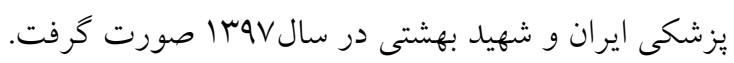
يزّوهشخر يس از كسب معرفى نامه از دانشخاه علوم

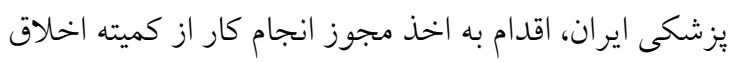

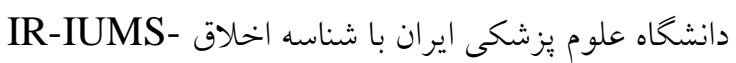

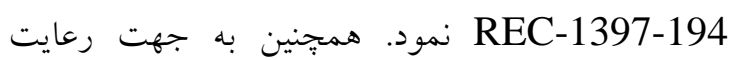
موازين اخلاقى، در ابتدا قبل از انجام يُزوهش، به افراد

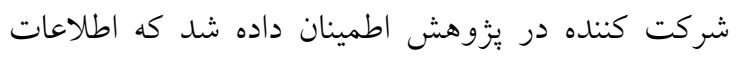

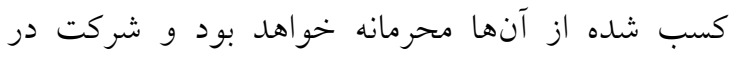
يزوهش به صورت اختيارى بوده و هر زمان كه تمايل

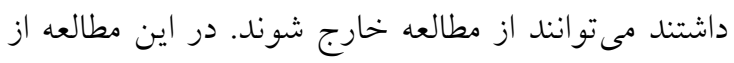
روش نمونه گيرى طبقهاى با تخصيص متناسب استفاده شد.

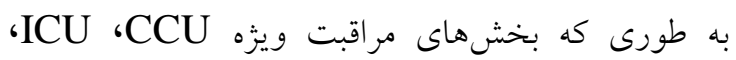
ICU-OH منظور نمونهاى يزووهش از بيمارستانهاى منتخب دانشخاه
و كمبود تخت بخشهاى مراقبت ويزه، مراقبت از بيماران

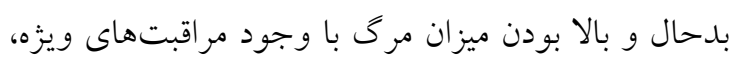

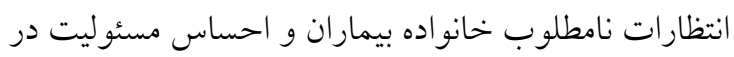
مورد مرى و زندكى بيماران و حمايت ناكافى از كاركنان

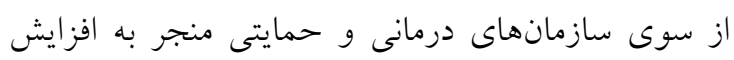

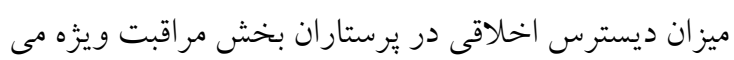

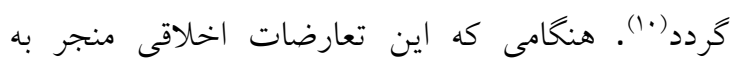
ناساز كارى اخلاقى و حرفهاى در برستاران شود به صورت

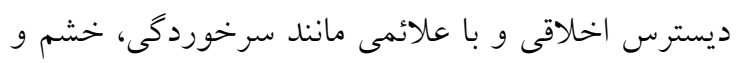

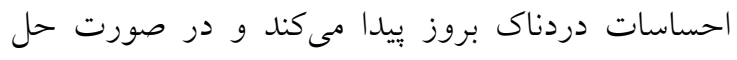

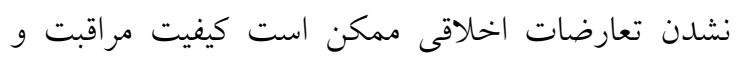
ايمنى بيمار را به خطر بياندازد و حتى باعث ترى حرفه

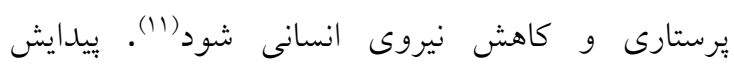
ديسترس اخلاقى در ميان يرستاران منجر به عصبانيت،

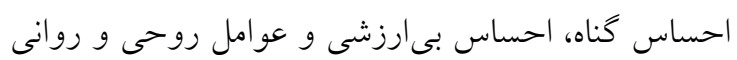

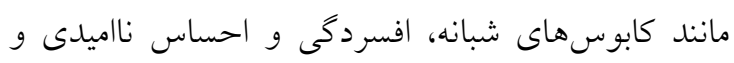

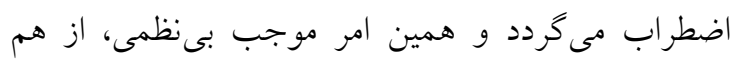

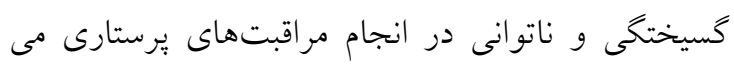

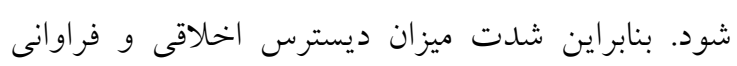

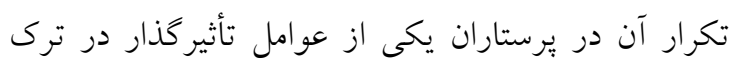

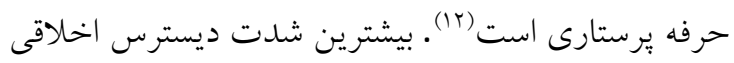
در بخش ويزهه به دليل ارائه مراقبت و درمان غير استاندارد به علت كمبود درمانكر و مراقبت دهندهى كافى بوده است. همجنين زمانى كه برستار مجبور به كار كردن با افراد فاقد دماند

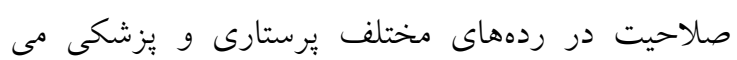

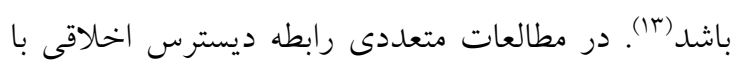
متغيرهاى جمعيت شناختى مانند سن، جنسيت و سابقه كارى گزارش شده است. به طورى كه عوامل جمعيت شناختى مىتوانند بر فراوانى و شدت ديسترس اخلاقيى

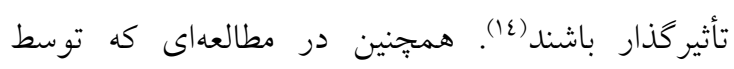
Dodak و همكاران انجام شد، كزارش شد كه سن به طور

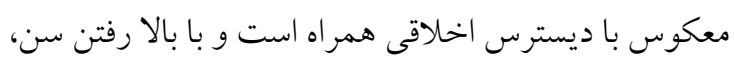

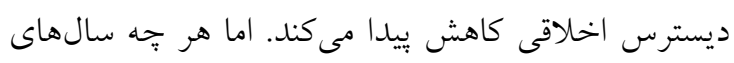

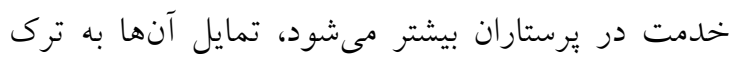


از جمع آورى و تغييرات لازم مجدداً ابزار، توسط دو نفر

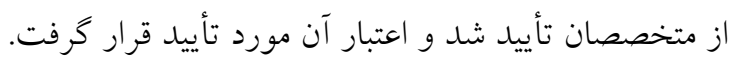

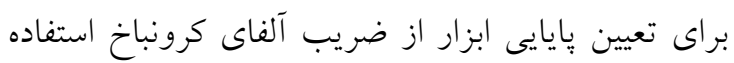

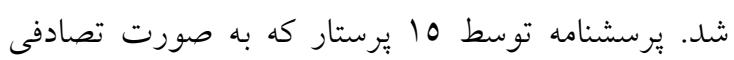

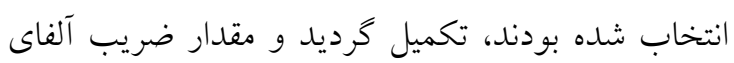

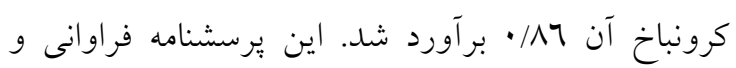
شدت ديسترس اخلاقى را بر حسب مقياس ليكرت

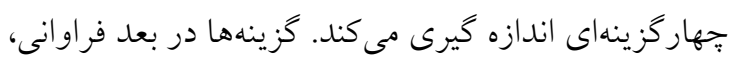

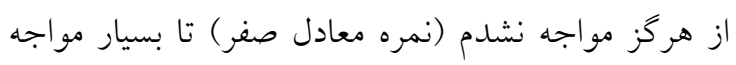

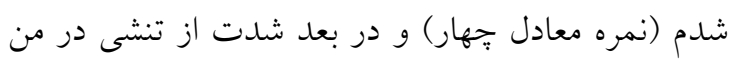

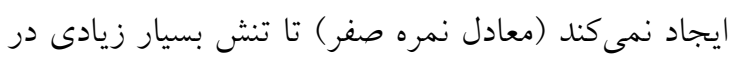

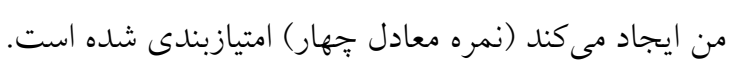

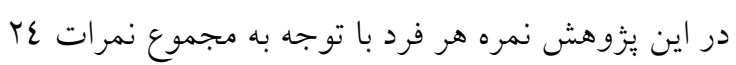

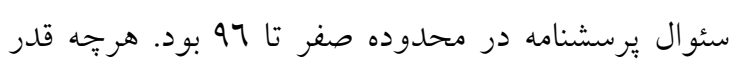

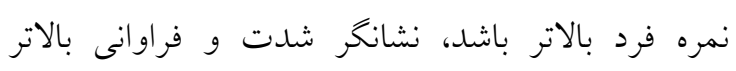
ديسترس اخلاقى است (iv). از آمار توصيفى شامل توزيع فراوانى و ميانخين و محاسبه شاخصهاى عددى براى توصيف نمونهها استفاده گرديد.

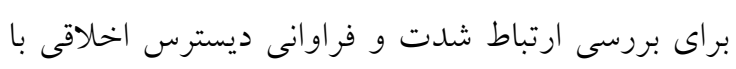

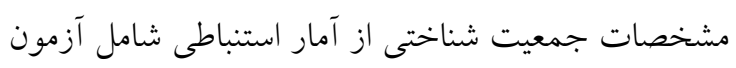

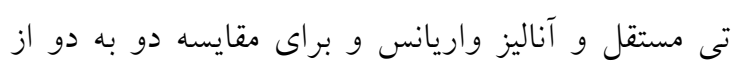
آزمون تعقيبى شفه استفاده شد. تحليل دادهها با استفاده از

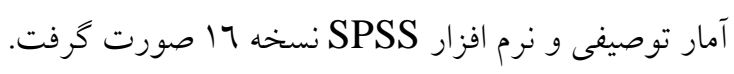

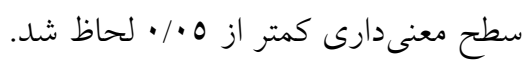

يافتهها

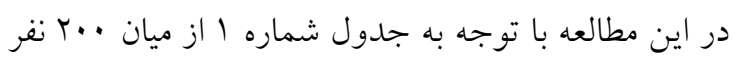

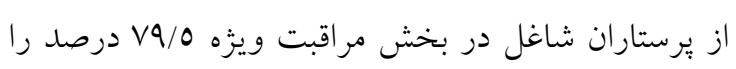

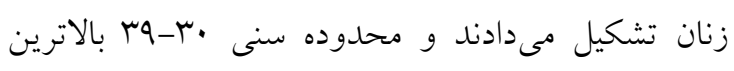

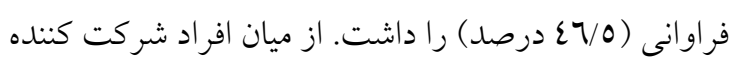

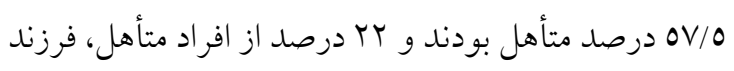

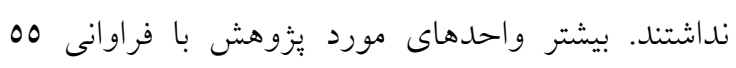

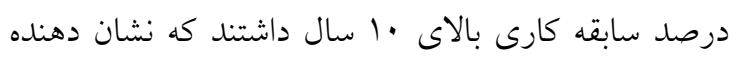

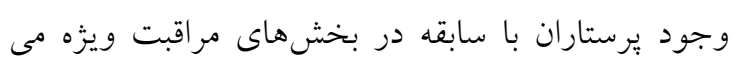

هاى علوم يزشكى ايران و علوم يزشكى شهيد بهشتى شهر

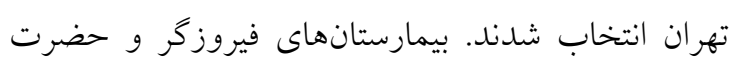

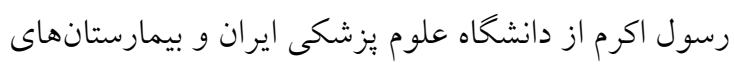

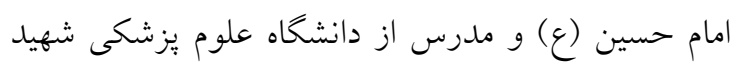

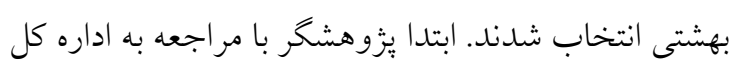

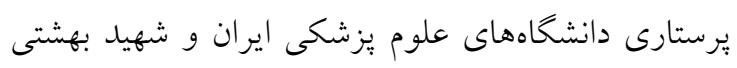

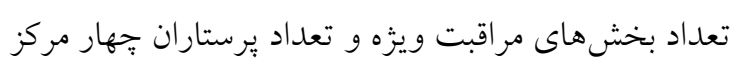

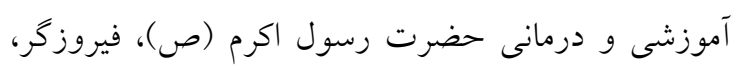

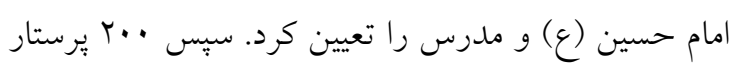

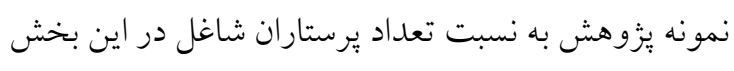

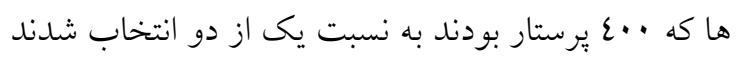

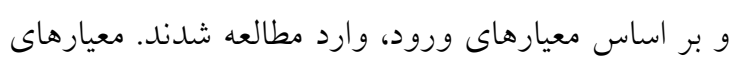
ورود به مطالعه شامل مدرى تحصيلى كارشناسى و بالاتر و داشتن حداقل يك سال سابقه كار در بخش مراقبت ويزه

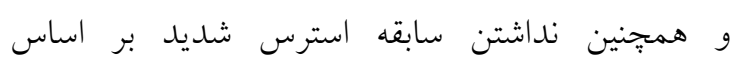
خوداظهارى (حوادث غيرمترقبه، تصادف شديد، طلاق، مرك يكى از نزديكان طى يك ماه اخير) بود.

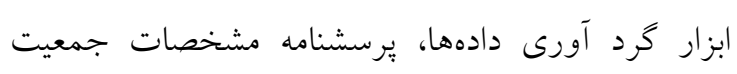
شناختى بود كه اين يرسشنامه در بردارنده اطلاعات زمينه

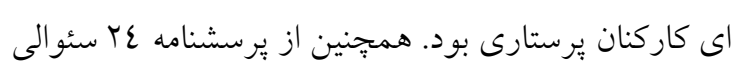
Corly

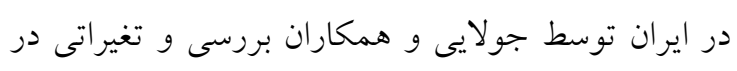

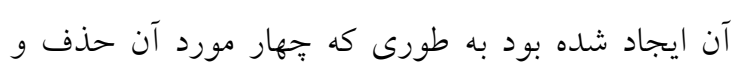

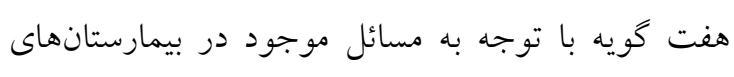

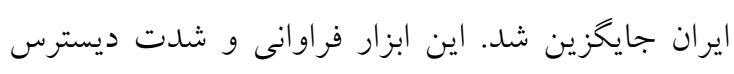

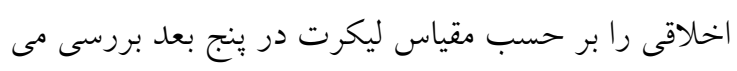

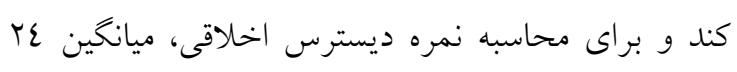

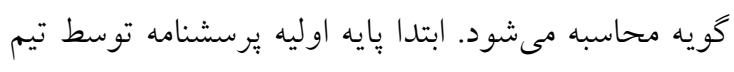

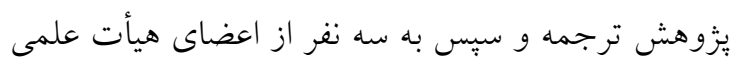
كه علاوه بر داشتن تخصص در زمينه مورد مطالعه به زبان

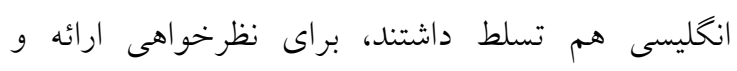
اصلاحات لازم صورت گرفت. همجنين براى تعيين اعتبار

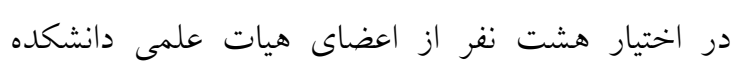

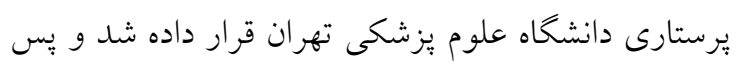


تعداد شيفت شب در ماه و آموزش اخلاق وجود نداشت

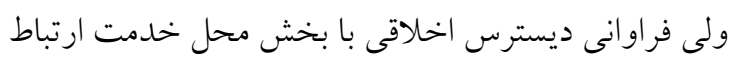

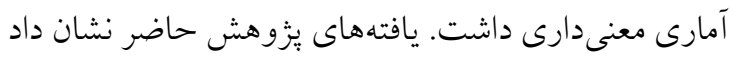

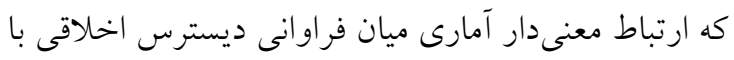

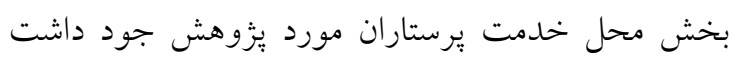

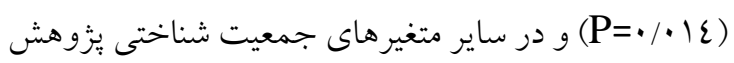

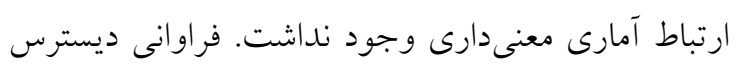

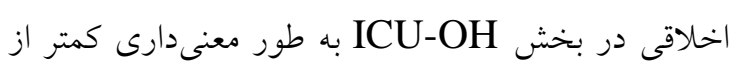

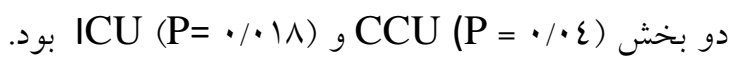
در دو بخش ICU و CCU اين اختلاف معنىدار نبود (جدول شماره (1). هم:جنين ارتباط معنى دار آمارى ميان

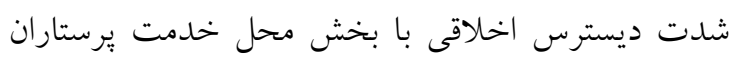

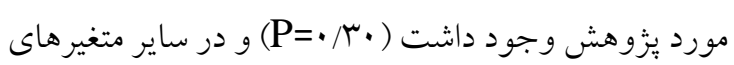

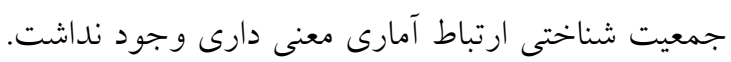

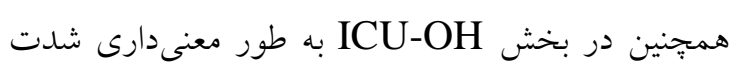

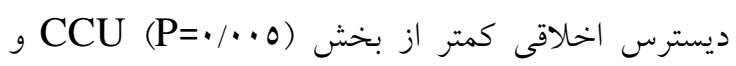

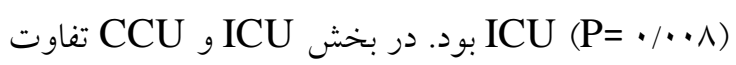

$$
\text { معنى دارى وجود نداشت (جدول شماره (). }
$$

باشد. همجنين NV/0 درصد واحدهاى مورد يزوهش داراى مدرى كارشناسى و باقى داراى مدرى كارشناسى ارشد بودند. 07/0 درصد به صورت استخدام رسمى مشغول به به دارئ

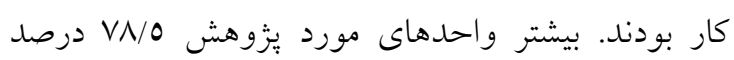

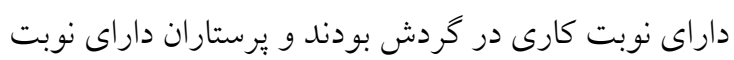

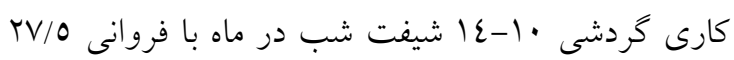

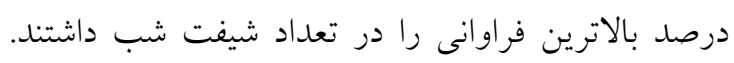

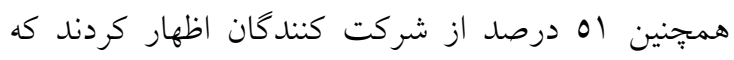

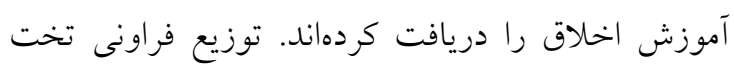

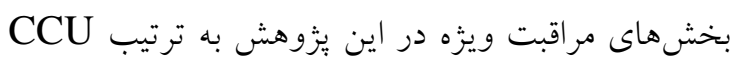

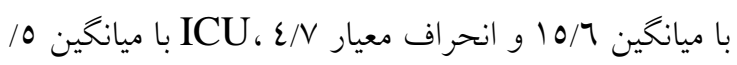

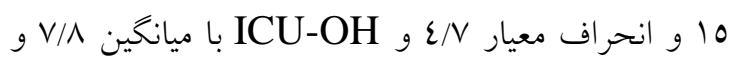

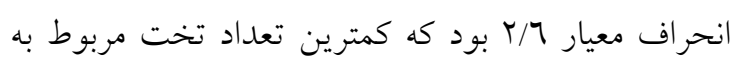
بخش ICU-OH بود. نتايج حاصل از آناليز واريانس و آزمون تى نشان داد كه بـان

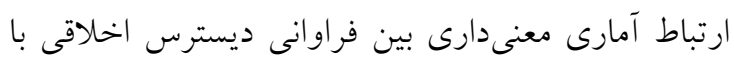

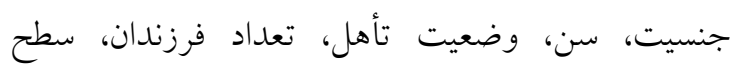
تحصيلات، سابقه كارى، وضعيت استخدامى، نوبت كارى،

جدول شماره (: شاخصهاى عددى فراوانى و شدت ديسترس اخلاقى بر حسب مشخصات جمعيت شناختى واحدهاى مورد بزوهش

\begin{tabular}{|c|c|c|c|c|c|c|c|c|c|}
\hline \multicolumn{3}{|c|}{ شدت ديسترس اخلاقى } & \multicolumn{3}{|c|}{ فراوانى ديسترس اخلاقى } & \multicolumn{4}{|c|}{ متغييرها } \\
\hline نتايج آزمون & معيار & ميانگين & نتايج آزمون & معيار انحراف & ميانغين & فر دراوانى & فراوانى & جمعيت شناختى & خصات \\
\hline$* t=|/ T|$ & $17 / 2 T$ & $\varepsilon \Lambda / q$ & $* t=\cdot / 70$ & $17 / 9$ & $\varepsilon V / r$ & $r \cdot 10$ & 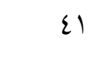 & 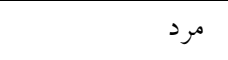 & جنسيت \\
\hline $\mathrm{df}=191$ & $\mid N / \Lambda \Lambda$ & Or/AE & $\mathrm{df}=191$ & $11 / 07$ & $\varepsilon q / \mu q$ & $\vee 9 / 0$ & 109 & زن & \\
\hline $\mathrm{P}=\cdot / K Y T$ & & & $\mathrm{P}=\cdot / 017$ & & & & & & \\
\hline$* * \mathrm{~F}=$ & $1 N / 7 \varepsilon$ & $\sum q / Y Y$ & $* * F=1 / 1 V \varepsilon$ & IN/No & $\varepsilon \tau / T$. & $r q / 0$ & 09 & زير •rr & \\
\hline $1 / \cdot \varepsilon \mathrm{P}$ & $\mathrm{IV} / \mathrm{V} \varepsilon$ & or/7l & $\mathrm{P}=\cdot / \mu 11$ & IV/TY & $0 . / \Lambda r$ & $\varepsilon 7 / 0$ & $q 4$ & .rتا & سن، سال \\
\hline$=. / r 00$ & $19 / 2 V$ & $O r / \varepsilon O$ & & $11 / 09$ & $\varepsilon \wedge / \vee \wedge$ & $r \varepsilon$ & r^ & • ع به بالا. & \\
\hline$* \mathrm{t}=1 / \mathrm{VV}$ & 1N/TO & $\varepsilon q / \mu q$ & $* \mathrm{t}=1 / 20$ & $1 N / 1 T$ & $\varepsilon \tau / V \varepsilon$ & $\varepsilon$ & NT & مجرد & وضعيت \\
\hline $\mathrm{df}=190$ & IN/OV & $0 \varepsilon / \cdot 1$ & $\mathrm{df}=190$ & $11 / \cdot 1$ & $0 . / 07$ & $0 V / 0$ & 110 & متأهل ل & تأهل \\
\hline $\mathrm{P}=\cdot / v \wedge$ & & & $\mathrm{P}=\cdot / \backslash \Sigma \wedge$ & & & & & & \\
\hline$* * \mathrm{~F}=|/ \Gamma|$ & $11 / 0$ & $01 / 11$ & $* \mathrm{~F}=\cdot / 107$ & IV/TI & $\varepsilon 9 / \mathrm{VV}$ & Tr & 2o & فرزند ندارد & تعداد \\
\hline \multirow[t]{4}{*}{$\mathrm{P}=\cdot \mu \cdot r$} & $11 / 09$ & or & $\mathrm{P}=\cdot / 100$ & $|V / A|$ & $0 . / T V$ & 11 & rV & يك فرزند دارد & 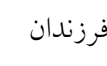 \\
\hline & $17 / 17$ & $O V / 9 V$ & & $19 / 7 V$ & $O T / \cdot T$ & IV & ro & دو فرزند دارد & \\
\hline & & & & & & r & $\varepsilon$ & سهوبيشترفرزند دارد & \\
\hline & 1N/rT & $O Y / O$ & & $1 \Lambda / r q$ & $\varepsilon 9 / \mu V$ & $\wedge V / 0$ & IVo & كارشناسى & \\
\hline
\end{tabular}




\begin{tabular}{|c|c|c|c|c|c|c|c|c|c|}
\hline $\begin{array}{l}* \mathrm{t}=1 / \cdot \vee 9 \\
\mathrm{df}=19 \wedge \\
\mathrm{P}=\cdot / r \wedge r\end{array}$ & $19 / 1$ & $\varepsilon \Lambda / r$ & $\begin{array}{l}* \mathrm{t}=\cdot / \wedge \mathrm{r}_{0} \\
\mathrm{df}=19 \wedge \\
\mathrm{P}=\cdot / \varepsilon \cdot \diamond\end{array}$ & 00 & $\{7 / 1 Y$ & $1 T / 0$ & ro & كارشناسى ارشد & تحطيلح \\
\hline$* * \mathrm{~F}=1 / Y 7 \mathrm{r}$ & $M / N V$ & 0./T & $* * F=\cdot / \wedge r$ & IV/Tr & $\{7 / 17$ & $r y / 0$ & or & كمتر از 0 & سابقه \\
\hline \multirow[t]{3}{*}{$\mathrm{P}=\cdot / \Gamma \Lambda \Lambda$} & IN/VY & $\{N / r\}$ & $\mathrm{P}=\cdot / \varepsilon V$ & $r T / \varepsilon V$ & $\{V / q)$ & $1 N / 0$ & rv & O تاه & كارى، \\
\hline & $17 / 09$ & $00 / 1$ & & $10 / 11$ & $01 / \varepsilon 1$ & $T V / 0$ & 00 & •اتاع| & سال \\
\hline & $19 / 1 \mathrm{~V}$ & $0 r / 11$ & & $11 / 0$. & $\left.\sum 9 / 9\right\}$ & $T V / 0$ & 00 & 10 به بالا & \\
\hline$* * \mathrm{~F}=\cdot / 10 \wedge$ & $11 / 01$ & or & $* * F=\cdot / \varepsilon V$ & $17 / 91$ & $\{9 / 0\}$ & $07 / 0$ & 111 & رسمى & \\
\hline \multirow[t]{4}{*}{$\mathrm{P}=\cdot / 7 \mathrm{VV}$} & $r \cdot / N$ & $0 . / \mathrm{VV}$ & $\mathrm{P}=\cdot / \mathrm{V} r$ & TY/NV & $\varepsilon \Lambda / T \varepsilon$ & $10 / 0$ & $\mu_{1}$ & ييمانى & وضعيت \\
\hline & $17 / 70$ & $0\{/ 17$ & & $\mid N / r \varepsilon$ & $01 / 70$ & 7 & ir & قراردادى & استخدامى \\
\hline & $17 / 9$ & $\{N / \cdot q$ & & $I V / r$ & $20 / 27$ & 17 & rt & طرحى & \\
\hline & $\mid N / T \Lambda$ & $O \varepsilon / V_{0}$ & & $r \cdot / r r$ & Or/TO & 7 & ir & شركتى & \\
\hline$* * \mathrm{~F}=\cdot /\{71$ & $r Y / \cdot \Lambda$ & $00 / \mu 7$ & $* * F=\cdot / \varepsilon\urcorner$ & $19 / 29$ & or & $1 T / 0$ & ro & صبح ثابت & نوبت \\
\hline \multirow[t]{2}{*}{$\mathrm{P}=\cdot / \pi T r$} & $10 / 71$ & $01 / 71$ & $\mathrm{P}=\cdot / 7 r$ & $1 V / 94$ & $\varepsilon \vee$ & 9 & 11 & شب ثابت & كارى \\
\hline & $1 N / \Gamma \varepsilon$ & $01 / 07$ & & $1 N / \cdot 0$ & $\{\Lambda / V)$ & $V N / O$ & $10 \mathrm{~V}$ & شيفت در كردش & \\
\hline$* * F=\cdot / r r$ & $r \cdot / r T$ & $01 / 91$ & $* * F=\cdot / 71$ & $r \cdot / 9 T$ & $\varepsilon \Lambda / Y\rceil$ & $r y / 0$ & or & ن ندارد & تعداد \\
\hline \multirow[t]{4}{*}{$\mathrm{P}=\cdot / \mathrm{T}$} & $\mid r / \cdot V$ & 07 & $\mathrm{P}=\cdot / 70$ & $1 \cdot 19 r$ & $O r / \varepsilon l$ & $\Lambda / 0$ & IV & كمتر ازع & شيفت \\
\hline & $11 / V q$ & $0 . / v 9$ & & $|N / \varepsilon|$ & $\varepsilon \tau / T \Lambda$ & TV & or & O 9 تا 9 & شب در \\
\hline & $\mid N / \cdot 1$ & $0 r / 79$ & & $I V / T r$ & $0 . / 77$ & $r q / 0$ & 09 & $\mid \varepsilon-1$. & ماه \\
\hline & $19 / \cdot 1$ & $\varepsilon q / 9 \varepsilon$ & & $1 N / T$. & $\{\Lambda / 11$ & N/O & IV & 10 و و بيشتر & \\
\hline$* * F=7 / 11$ & $1 N / \cdot 0$ & or/lE & $* * F=\varepsilon / \mu q$ & $1 N / T_{0}$ & $0 . / 19$ & $7 \pi / 0$ & ITV & ICU & \\
\hline \multirow[t]{2}{*}{$\mathrm{P}=\cdot / \cdot r$} & $19 / 2$ & $00 / \mathrm{VV}$ & $\mathrm{P}=\cdot / \cdot 1 \varepsilon$ & IVTro & $0 \cdot / \wedge \varepsilon$ & rt & $\varepsilon \varepsilon$ & $\mathrm{CCU}$ & بخش \\
\hline & $10 / 1 \mathrm{~V}$ & $\varepsilon 1 / 00$ & & $18 / 17$ & $r q / \wedge r$ & $1 \varepsilon / 0$ & rq & ICU OH & \\
\hline$* t=\cdot / \wedge \varepsilon$ & $19 / 77$ & $0 . / 97$ & $* t=1 / 7 r$ & $1 V / 9 T$ & $\varepsilon 7 / 9 r$ & 01 & $1 \cdot r$ & بله & آموزش \\
\hline $\mathrm{df}=191$ & & & $\mathrm{df}=191$ & & & $\varepsilon 9$ & 91 & خير & اخلاق \\
\hline $\mathrm{P}=\cdot / \varepsilon$. & & & $\mathrm{P}=\cdot / 1 \cdot 7$ & & & & & & \\
\hline
\end{tabular}

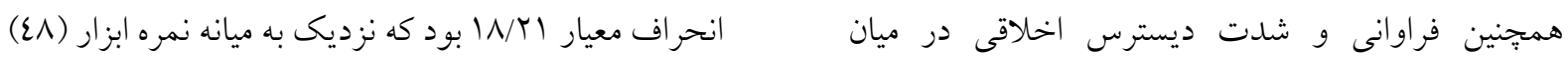

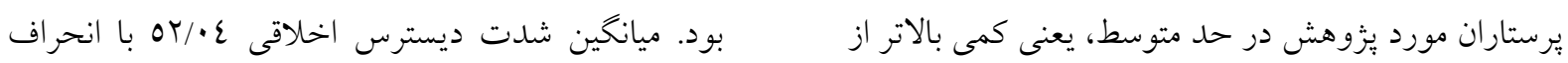

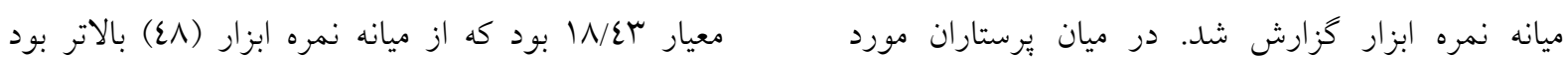

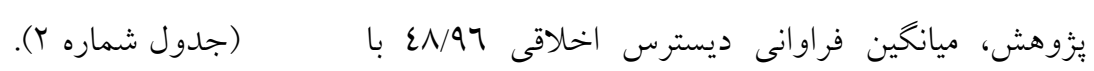

جدول شماره ז: ميانكَين و انحراف معيار فراوانى و شدت ديسترس اخلاقى در ميان يرستاران مورد يزوهش يُش

\begin{tabular}{|c|c|c|c|c|}
\hline انحر اف معيار & ميانكين & بيشينه & كمينه & ديسترس اخلاقى (دامنه نمرات ابزار ·-47ه \\
\hline $17 / 94$ & $\varepsilon \tau / 7 \varepsilon$ & $\wedge \vee$ & 7 & فراوانى ديسترس اخلاقى \\
\hline $\mid N / \varepsilon r$ & $O r / \cdot \varepsilon$ & $9 \varepsilon$ & 0 & شدت ديسترس اخلاقى \\
\hline
\end{tabular}


شدت مواجه با ديسترس اخلاقى نيز مربوط به سئوال ع

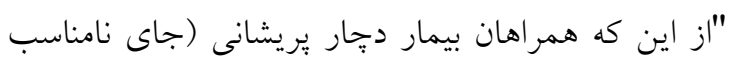
استراحت، عدم آكاهى از حقوق بيمار و خانواده) هستند،

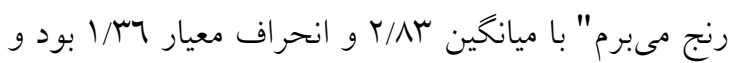
كمترين ميانخين شدت ديسترس اخلاقى مربوط به سئوال

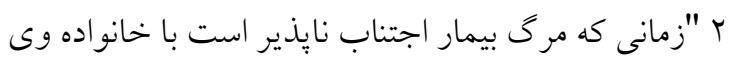
در مورد اهداى عضو صحبت مى كنم" با ميانخين اسما و و

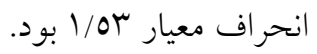

نتايج جدول شماره ץ بيانگر اين بود كه بيشترين فراوانى دفعات مواجهه با ديسترس اخلاقى مربوط به سئوال عائ مبنى بر "از اين كه همراهان بيمار دجّار بريشانى (جاى نامناسب استراحت، عدم آكاهى از حقوق بيمار و خانواده)

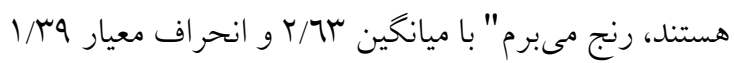
بود. كمترين فراوانى دفعات مواجهه با ديسترس اخلاقى مربوط به سئوال r "زمانى كه مرگ بيمار اجتناب نايذير است با خانو اده وى در مورد اهداى عضو صحبت مى كنم" مسته

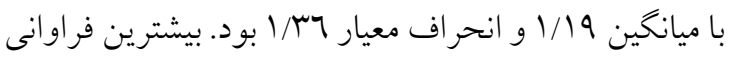

جدول شماره سا: توزيع فراوانى و ميانكين مواجهه باو سطح يا شدت ديسترس اخلاقى فروانى و دفعات مواجهه با سطح يا شدت ديسترس اخلاقى

\begin{tabular}{|c|c|c|c|}
\hline & & ل اخلاقى & \\
\hline انحر افمعيار & ميانگين & انحراف معيار & ميانخين \\
\hline
\end{tabular}
نيروى انسانى) نمى توانم خدمات مطلوبى به بيمار ارائه دهم

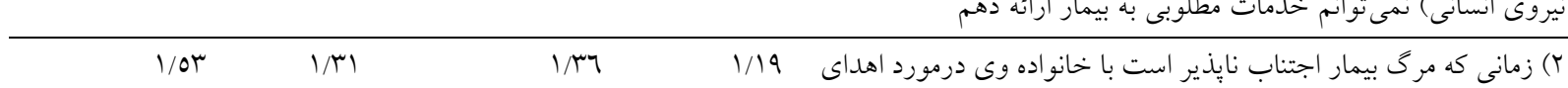

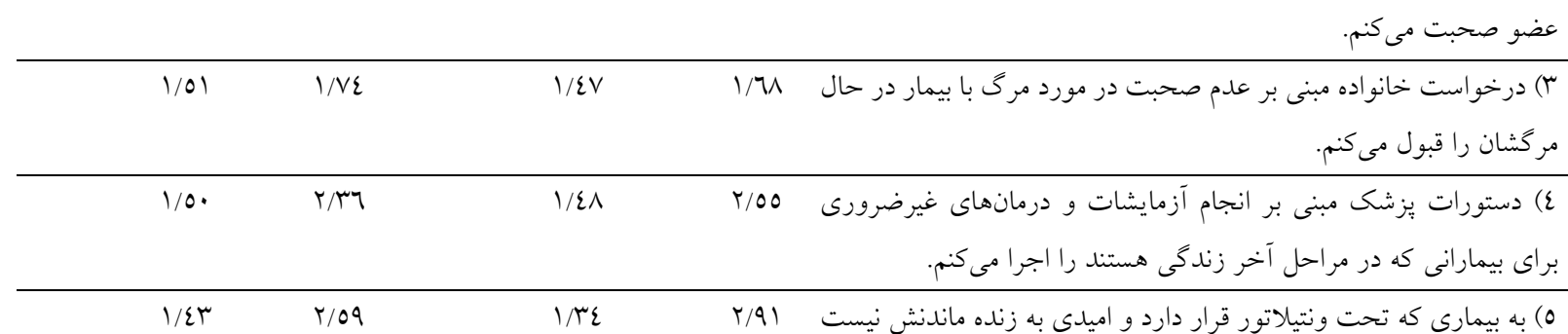

\begin{tabular}{|c|c|c|c|c|}
\hline $1 / \varepsilon \wedge$ & $r / \cdot V$ & $1 / \pi 9$ & $1 / 90$ & 7) از دستور يزشك مبنى بر نخفتن حقيقت به بيمارى كه سئوال مى كند \\
\hline & & & & تبعيت مى كنم \\
\hline $1 / 0 r$ & $r / \mu \varepsilon$ & $1 / 乏 \wedge$ & $r / r \varepsilon$ & (V) به يزشكى كه به نظرم صلاحيت مراقبت از بيمار را ندارد كمك مى كنم \\
\hline 1/or & $r / r u$ & $1 / \% q$ & $1 / 99$ & ^) وقتى دانشجويان صرفاً براى بالا بردن مهارتهاى خود اعمال دردناك \\
\hline
\end{tabular}

\begin{tabular}{|c|c|c|c|c|}
\hline & & & & را روى بيمار انجام مىدهند سكوت كرده و اعتراضى نمىكنم \\
\hline $1 / \mu \cdot$ & $r / \mu \varepsilon$ & $1 / T V$ & $r / 10$ & 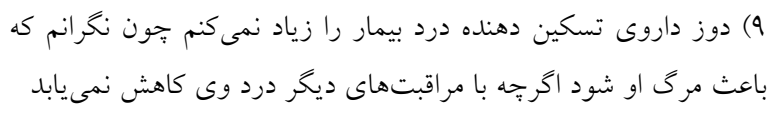 \\
\hline $1 / 0$. & $1 / 90$ & $1 / 20$ & $1 / 9$. & • (1) درخواست يزشك مبنى بر عدم صحبت كردن با خانو اده بيمار در \\
\hline
\end{tabular}

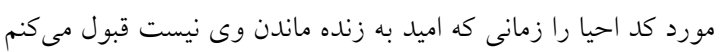

\begin{tabular}{|c|c|c|c|c|}
\hline $1 / 0 \mathrm{~V}$ & $1 / 94$ & $1 / 0 \mathrm{~V}$ & $r / \cdot r$ & | (1) درخو است شفاهى يزشك مبنى بر No code بودن بيمار را مىيذيرم \\
\hline \multirow[t]{2}{*}{$1 / 0 \varepsilon$} & INT & $1 / 02$ & $1 / V_{0}$ & Y I ) درخواست يزشك مبنى بر عدم گفتخو در مورد مرگ با بيمار در حال \\
\hline & & & & احتضار را قبول مى كنم \\
\hline $1 / 01$ & $T / Y V$ & $1 / 79$ & $r / \cdot \cdot$ & با (1) با همكارانى كه م \\
\hline
\end{tabular}




\begin{tabular}{|c|c|c|c|c|}
\hline $1 / 71$ & T/Kr & $1 / 0 r$ & $1 / 9 V$ & نشان نمى (1) در صورت مشاهده مو اردى كه به حريم بيمار تجاوز مىشود و اكنشى \\
\hline 1/or & $r / 11$ & $1 / \varepsilon r$ & $1 / A V$ & 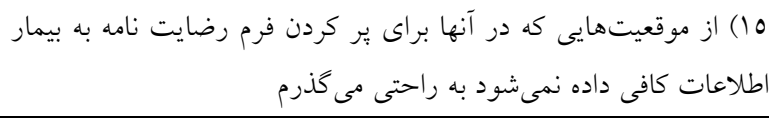 \\
\hline $1 / 01$ & $1 / 90$ & $1 / \Gamma V$ & $1 / V 7$ & را 11 ابا بيمار اجرا مرخى يزشنم مبنى بر عدم صحبت كردن در مورد وضعيت احيا \\
\hline $1 / \varepsilon V$ & $r / \backslash \Lambda$ & $1 / \varepsilon r$ & $r / \cdot r$ & به كترل درد نيست ادامه مىدهم ضد درد را حتى زمانى كه داروى تجويز شده قادر \\
\hline $1 / 0 \varepsilon$ & $1 / 99$ & $1 / \varepsilon 1$ & I/AT & علاج 1) درخواست يزشك مبنى بر كنتكو با خانو اده در مورد تشخيص بيمارى غيرقابل \\
\hline $1 / 07$ & $r / \bullet \Lambda$ & $1 / \varepsilon \varepsilon$ & $1 / V V$ & نمى كنم ملى رغم مشاهده تبعيض در ارائه خدمات مر اقبتى به بيماران اعتراضى \\
\hline $1 / 2 \Lambda$ & $T / Y)$ & $1 / \Gamma V$ & $1 / 94$ & •r) اشتباهات همكارانم رادر مراقبت از بيمار ان ناديده مى كيرم \\
\hline $1 / \varepsilon \wedge$ & T/Mo & $1 / \mu \wedge$ & $1 / 99$ & با (Y) به دليل تعداد زياد بيماران قادر به ارائه مراقبت با كيفيت به انان نيستم \\
\hline $1 / 0$ & $r / \cdot \varepsilon$ & $1 / \Gamma \wedge$ & 1/V0 & مى كنند من سكوت همكاران از آكَاهى دادن به بيماران در مورد حقوقشان خودارى \\
\hline $1 / 20$ & $r / \varepsilon$ & $1 / \varepsilon r$ & $T / Y I$ & مى بr) از اين كه فرصت كافى براى آموزش به بيمار و خانواده ندارم رنج \\
\hline $1 / \% 7$ & T/Ar & $1 / \pi q$ & $r / \tau r$ & 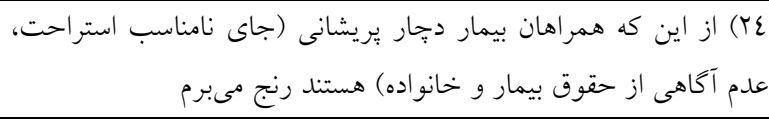 \\
\hline
\end{tabular}

شهر بيرجند در حد متوسط بود(rr) كه نتايج اين دو مطالعه همسو با نتايج مطالعه حاضر است. در مطالعهاى كه توسط

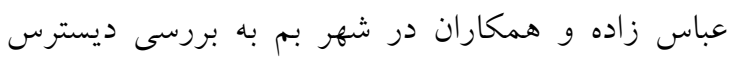
اخلاقى در يرستاران شاغل زيرداخته است، ميزان شدت ديسترس اخلاقى در حد متوسط كزارش شد كه با مطالعه

$$
\text { حاضر همسو است (17). }
$$

همجنين در اين مطالعه ميان ديسترس اخلاقى و عوامل جمعيت شناختى ارتباط معنىدارى گزارش نشد و نتايج اين بززوهش نشان داد كه فقط بخش محل خدمت ارتباط معنى دارى با ديسترس اخلاقى داشت. نتايج مطالعه Ohnishi زاين نشان داد كه فراوانى ديسترس اخلاقى مىتواند بانوع بخش محل خدمت در ارتباط باشد (rr). مطالعه صادقى و و

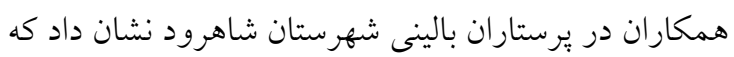
ديسترس اخلاقى در يرستاران بخشهاى مختلف متفاوت بود و اختلاف معنىدارى وجود داشت به طورى كه

\section{بحث و نتيجه كيرى} در اين ئزوهش فراوانى ديسترس اخلاقى در يرستاران بخش مراقبت ويزه در حد متوسط گزارش شد. در مطالعه بيك مرادى در برستاران بخششهاى مراقبت ويزه در مراكز آموزشى و درمانى شهر همدان ديسترس اخلاقى در حد متوسط كزارش شد (1). همجنين در مطالعه برهانى و و همكاران در بيمارستانهاى آموزشى شهر بيرجند، فراوانى ديسترس اخلاقى در حد متوسط گزارش گرديد (19). Elpern و همكاران، ديسترس اخلاقى را در : يرستاران بخشهاى مراقبت ويزه شيكاگو آمريكا، متوسط گزارش كردند (r) (r) همجنين در اين مطالعه شدت ديسترس اخلاقى در يرستاران بخش مراقبت ويزه در حد متوسط كزارش شد. مطالعه صادقى و همكاران در شاهرود نشان داد كه ميزان شدت ديسترس اخلاقى در حد متوسط بود (YI). همجينين در مطالعه برهانى و همكاران شدت ديسترس اخلاقى در 
همجنين در زمينه آموزش اخلاقى در مطالعه حاضر، رابطه

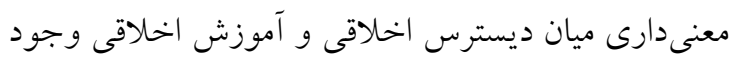

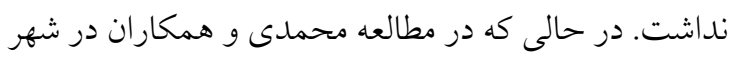

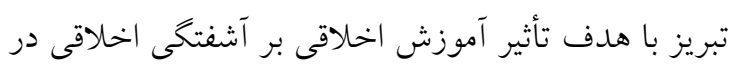

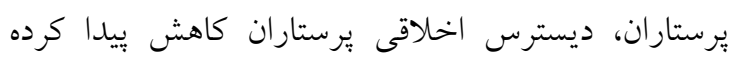

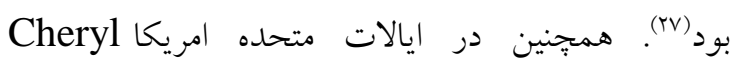
Rathert

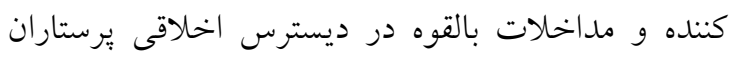

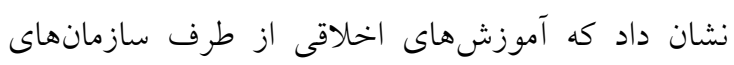

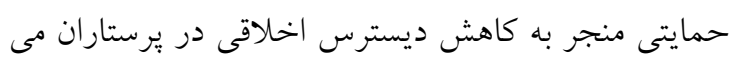
شود كه با نتايج مطالعه حاضر در تناقض است (ه).

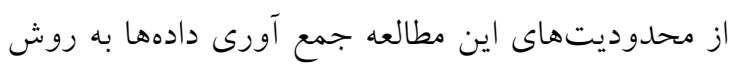

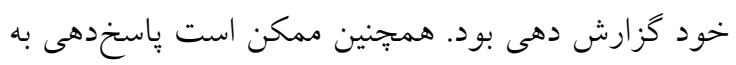

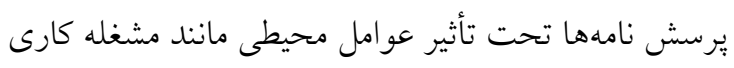

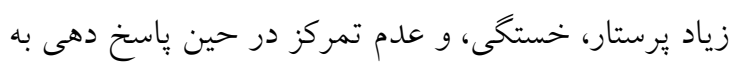

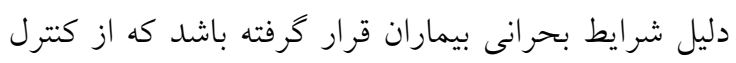
ئزوهشخر خارج است.

بر اساس يافتهاى يُزوهش، مشخصات جمعيت شناختى

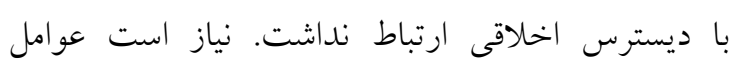
ديخرى مانند حمايت سازمانى، عوامل اقتصادى و عوامل

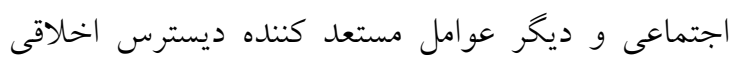

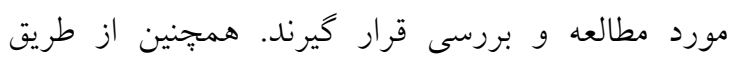

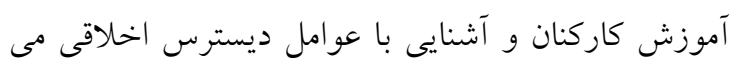

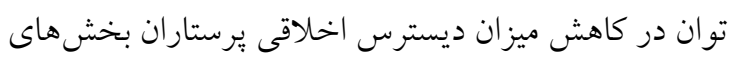
مراقبت ويزه تلاش نمود. اين امر مىتواند از طريق استادان

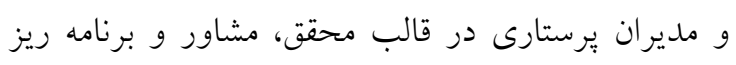

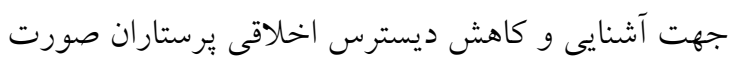

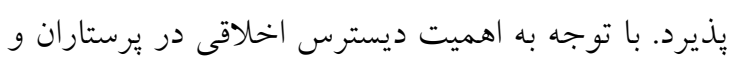

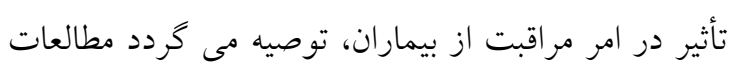

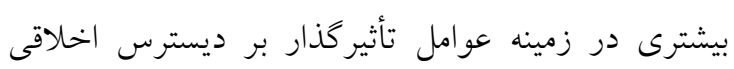

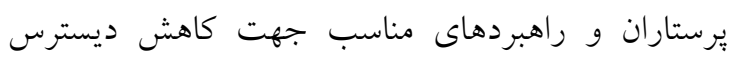
اخلاقى آنان انجام كيرد.
بالاترين ديسترس اخلاقى در بخش هاى ICU، ارتويدى

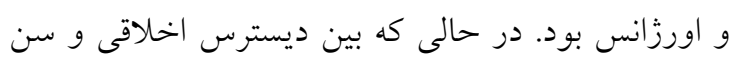

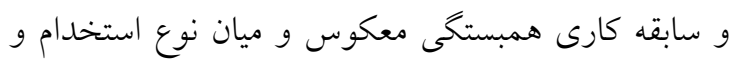

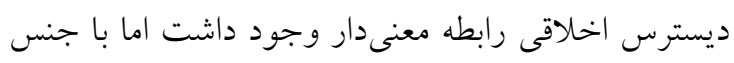

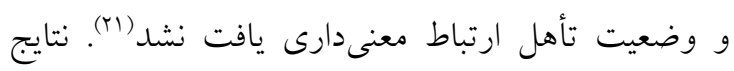
مطالعه آنها با برخى از نتايج مطالعه حاضر همسو مى باشئد.

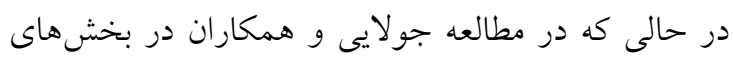

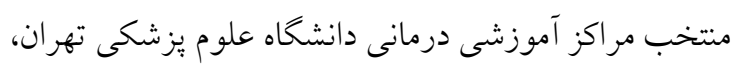

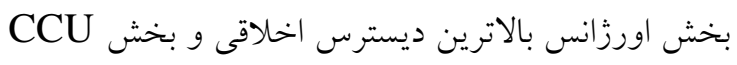

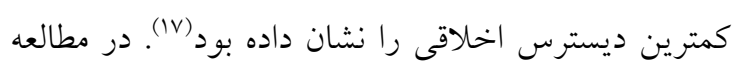

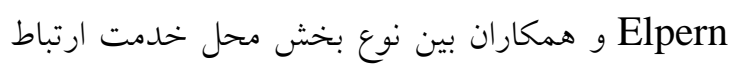

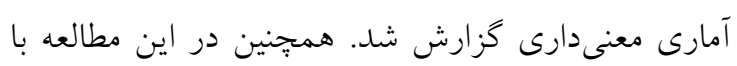

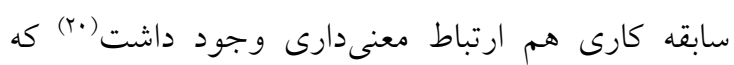

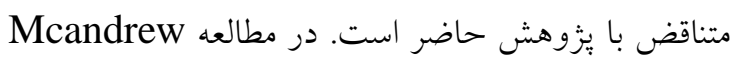
و همكاران كه به صورت مرور نظاممند انجام شد، ارتباط

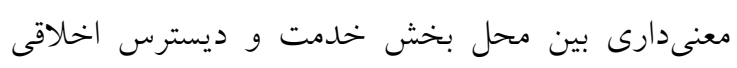

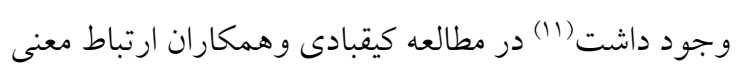

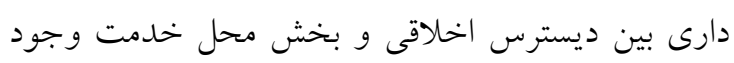

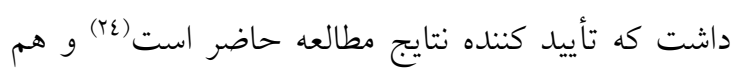

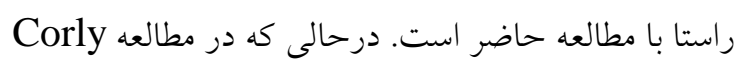

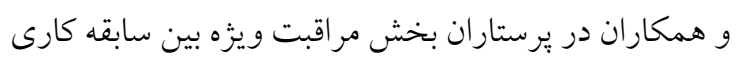

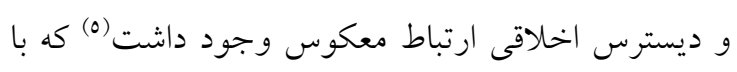
مطالعه حاضر مغاير بود. مطالعه Hamaideh و همكاران

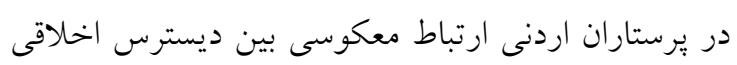

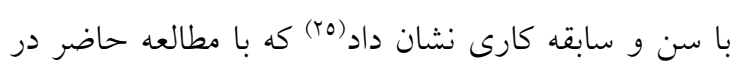

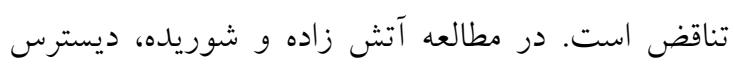
اخلاقى با وضعيت تأهل، سطح تحصيلات و نوع استخدام

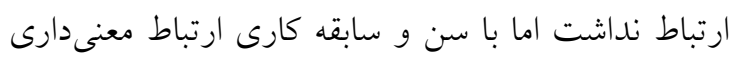

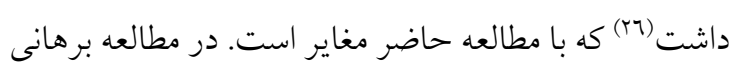
و همكاران كه در مراكز آموزشى و درمانى دانشخاه علوم يزشكى شهيد بهشتى شهر تهران صورت كرفت از ميان

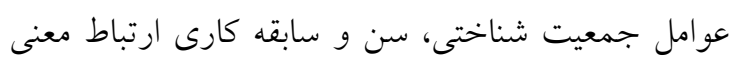

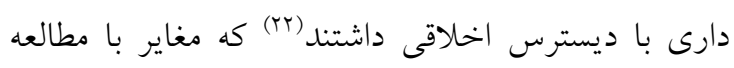

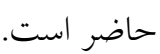




$$
\begin{aligned}
& \text { تمامى يرستاران منتخب بخشهاى مراقبت ويزَه مراكز }
\end{aligned}
$$

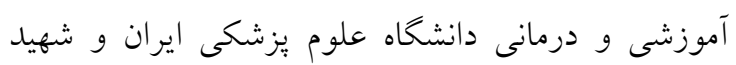

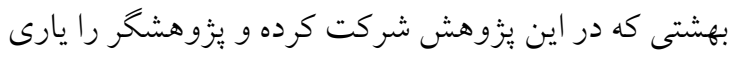

$$
\begin{aligned}
& \text { كردهاند، قدردانى و تشكر مىنمايند. }
\end{aligned}
$$

\section{References}

1. Humeniuk E, Dąbska O, Pawlikowska-Łagód K, Goś A. Occupational stress in nursing-review of studies in chosen hospital wards of Eastern Poland. Journal Of Public Health, Nursing And Medical Rescue. 2017;207(2017_1):14-20.

2. Ramos AM, Barlem EL, Barlem JG, Rocha LP, Dalmolin GD, Figueira AB. Cross-cultural adaptation and validation of the Moral Distress Scale-Revised for nurses. Rev Bras Enferm. 2017;70(5):1011-7.

3. McCarthy J, Deady R. Moral distress reconsidered. Nursing Ethics. 2008;15(2):254-62.

4. Shoorideh FA, Ashktorab T, Yaghmaei F, Alavi Majd H. Relationship between ICU nurses' moral distress with burnout and anticipated turnover. Nursing Ethics. 2015;22(1):64-76.

5. Corley MC, Minick P, Elswick RK, Jacobs M. Nurse moral distress and ethical work environment. Nursing Ethics. 2005;12(4):381-90.

6. Aarabi, A, Pahlavan Zadeh S, Joolaee S, Riahi M. Shahriari, M. Ethics and Law in Nursing and Midwifery, Esfahan: Isfahan University Of Medical Sciences. 2013. [Persian]

7. Ersoy N, Akpinar A. Turkish nurses' decision making in the distribution of intensive care beds. Nursing Ethics. 2010;17(1):87-98.

8. Rathert C, May DR, Chung HS. Nurse moral distress: A survey identifying predictors and potential interventions. Int J Nurs Stud. 2016 1;53:39-49.

9. Imani JA, Rezae HH, Mirzai M. Evaluation the effect of work conscientiousness and moral sensitivity with ethical stress in nurses working in intensive care units in educational and therapeutic centers affiliated to Zahedan University of Medical Sciences. Quarterly Journal of Iranian Society Anaesthesiology and Intensive Care Quarterly. 2018;2(4):20-7. [Persian]

10. Haghighinezhad G, Atashzadeh-Shoorideh F, Ashktorab T, Mohtashami J, BarkhordariSharifabad M. Relationship between perceived organizational justice and moral distress in intensive care unit nurses. Nursing Ethics. 2019;26(2):460-70.

11. McAndrew NS, Leske J, Schroeter K. Moral distress in critical care nursing: the state of the science. Nursing Ethics. 2018;25(5):552-70.

12. Lazzarin M, Biondi A, Di Mauro S. Moral distress in nurses in oncology and haematology units. Nursing Ethics. 2012;19(2):183-95.

13. Rahimi Madiseh M, Ayazi Z. Ethics and Professional ethics. Tehran Jame-e-Negar; 2015.

14. O'Connell CB. Gender and the experience of moral distress in critical care nurses. Nursing Ethics. 2015;22(1):32-42.

15. Dodek PM, Wong H, Norena M, Ayas N, Reynolds SC, Keenan SP, Hamric A, Rodney P, Stewart M, Alden L. Moral distress in intensive care unit professionals is associated with profession, age, and years of experience. J Crit Care. 2016;31(1):178-82.

16. Abbaszadeh A, Nakhaei N, Borhani F, Roshanzadeh M. The relationship between moral distress and retention in nurses in Birjand teaching hospitals. Iranian Journal of Medical Ethics and History of Medicine. 2013;6(2):57-66. [Persian]

17. Joolaee S, Jalili H, Rafiee F, Haggani H. The relationship between nurses' perception of moral distress and ethical environment in Tehran University of Medical Sciences. Iranian Journal of Medical Ethics and History of Medicine. 2011;4(4):56-66. [Persian] 
18. Beikrnoradi A, Rabiee S, Khatiban M, Cheraghi MA. Nurses distress in intensive care unit: a survey in teaching hospitals. Journal of Medical Ethics and History of Medicine. 2012;5(2): 5363. [Persian]

19. Borhani F, Mohammadi S, Roshanzadeh M. Moral distress and its relationship with professional stress in nurses. Iranian Journal of Medical Ethics and History of Medicine. 2014;6(6):10-9. [persian]

20. Elpern EH, Covert B, Kleinpell R. Moral distress of staff nurses in a medical intensive care unit. Am J Crit Care. 2005;14(6):523-30

21. Sadeghi M, Ebrahimi H, Aghayan S. Evaluation of the Moral Distress and Related Factors in Clinical Nurses of Shahroud City. Iranian Journal of Psychiatric Nursing. 2015;3(3):20-8. [Persian]

22. Borhani F, Abbaszadeh A, Mohamadi E, Ghasemi E, Hoseinabad-Farahani MJ. Moral sensitivity and moral distress in Iranian critical care nurses. Nursing Ethics. 2017;24(4):474-82.

23. Ohnishi K, Ohgushi Y, Nakano M, Fujii H, Tanaka H, Kitaoka K, Nakahara J, Narita Y. Moral distress experienced by psychiatric nurses in Japan. Nursing Ethics. 2010;17(6):726-40.

24. Keighobadi F, Sadeghi H, Keighobadi F, Tabaraei Y. The relationship between moral distress and emotional exhaustion in nurses. Iranian Journal of Medical Ethics and History of Medicine. 2014;7(3):36-47. [Persian]

25. Hamaideh SH. Moral distress and its correlates among mental health nurses in Jordan. Int J Ment Health Nurs. 2014;23(1):33-41.

26. Atashzadeh Shorideh F, Ashktorab T, Yaghmaei F, Alavimajd H. Association of ICU nurses' demographic characteristics and moral distress. Iranian Journal of Medical Ethics and History of Medicine. 2013;5(7):66-78. [Persian]

27. Mohamadi J, Ghazanfari F, Azizi A. The effectiveness of ethics training on nurses ethical distress. Journal of Medical Education Development. 2016;8(20):99-105. [Persian] 